\title{
TRPM2 Contributes to Inflammatory and Neuropathic Pain through the Aggravation of Pronociceptive Inflammatory Responses in Mice
}

\author{
Kayo Haraguchi, ${ }^{1}$ Ai Kawamoto, ${ }^{1}$ Kouichi Isami, ${ }^{1}$ Sanae Maeda, ${ }^{1}$ Ayaka Kusano, ${ }^{1}$ Kayoko Asakura, ${ }^{1}$ \\ Hisashi Shirakawa, ${ }^{1}$ Yasuo Mori, ${ }^{2}$ Takayuki Nakagawa, ${ }^{1}$ and Shuji Kaneko ${ }^{1}$ \\ ${ }^{1}$ Department of Molecular Pharmacology, Graduate School of Pharmaceutical Sciences, Kyoto University, Sakyo-ku, Kyoto 606-8501, Japan and \\ ${ }^{2}$ Department of Synthetic Chemistry and Biological Chemistry, Graduate School of Engineering, Kyoto University, Katsura Campus, Nishikyo-ku, Kyoto \\ 615-8510, Japan
}

Accumulating evidence suggests that neuroimmune interactions contribute to pathological pain. Transient receptor potential melastatin 2 (TRPM2) is a nonselective $\mathrm{Ca}^{2+}$-permeable cation channel that acts as a sensor for reactive oxygen species. TRPM2 is expressed abundantly in immune cells and is important in inflammatory processes. The results of the present study show that TRPM2 plays a crucial role in inflammatory and neuropathic pain. While wild-type and TRPM2 knock-out mice showed no difference in their basal sensitivity to mechanical and thermal stimulation, nocifensive behaviors in the formalin test were reduced in TRPM2 knock-out mice. In carrageenan-induced inflammatory pain and sciatic nerve injury-induced neuropathic pain models, mechanical allodynia and thermal hyperalgesia were attenuated in TRPM2 knock-out mice. Carrageenan-induced inflammation and sciatic nerve injury increased the expression of TRPM2 mRNA in the inflamed paw and around the injured sciatic nerve, respectively. TRPM2 deficiency diminished the infiltration of neutrophils and the production of chemokine (C-X-C motif) ligand-2 (CXCL2), a major chemokine that recruits neutrophils, but did not alter the recruitment of F4/80-positive macrophages in the inflamed paw or around the injured sciatic nerve. Microglial activation after nerve injury was suppressed in the spinal cord of TRPM2 knock-out mice. Furthermore, CXCL2 production and inducible nitric oxide synthase induction were diminished in cultured macrophages and microglia derived from TRPM2 knock-out mice. Together, these results suggest that TRPM2 expressed in macrophages and microglia aggravates peripheral and spinal pronociceptive inflammatory responses and contributes to the pathogenesis of inflammatory and neuropathic pain.

\section{Introduction}

Physiological pain is transient and necessary for the alarm system that warns us and helps to protect humans from tissue damage, while pathological pain is usually persistent due to plastically altered pain pathways and can be excruciating in daily life. Several lines of evidence suggest that neuroinflammation mediated by the interaction between immune cells and neurons plays an important role in pathological pain (Scholz and Woolf, 2007; Ren and Dubner, 2010). Resident and circulating immune cells, such as macrophages, neutrophils, T-lymphocytes and mast cells, infiltrate and become activated in responses to peripheral tissue

Received Sept. 14, 2011; revised Jan. 20, 2012; accepted Jan. 26, 2012.

Author contributions: K.H., A. Kawamoto, H.S., T.N., and S.K. designed research; K.H., A. Kawamoto, K.I., S.M., A. Kusano, K.A., H.S., and T.N. performed research; Y.M. and S.K. contributed unpublished reagents/analytic tools; K.H., H.S., T.N., and S.K. analyzed data; K.H., T.N., and S.K. wrote the paper.

Conflict of Interest: The authors declare no competing financial interests.

This work was supported in part by a Grant-in-Aid for Scientific Research from the Ministry of Education, Culture, Sport, Science and Technology of Japan and by grants from the Mochida Memorial Foundation for Medical and Pharmaceutical Research and the Suzuken Memorial Foundation.

Correspondence should be addressed to Dr. Takayuki Nakagawa, Department of Molecular Pharmacology, Graduate School of Pharmaceutical Sciences, Kyoto University, 46-29 Yoshida-Shimoadachi-cho, Sakyo-ku, Kyoto 6068501, Japan. E-mail:tnakaga@pharm.kyoto-u.ac.jp.

DOI:10.1523/JNEUROSCI.4703-11.2012

Copyright $\odot 2012$ the authors $\quad 0270-6474 / 12 / 323931-11 \$ 15.00 / 0$ damage, inflammation, or nerve injury. Pronociceptive inflammatory mediators such as proinflammatory cytokines, chemokines, and reactive oxygen/nitrogen species (ROS/RNS) released from the activated immune cells can induce the sensitization of nociceptors and increase the excitability of nociceptive primary afferent neurons (peripheral sensitization). The prolonged or intense hyperexcitability of peripheral nociceptive neurons triggers synaptic facilitation and enhances the responsiveness of nociceptive dorsal horn neurons (central sensitization). Accumulating evidence clearly suggests that the activation of spinal glial cells, such as microglia, is involved in the generation of central sensitization via the production of pronociceptive inflammatory mediators (Gao and Ji, 2010).

Transient receptor potential melastatin 2 (TRPM2), a member of the melastatin subfamily of TRP channels, forms a $\mathrm{Ca}^{2+}$ permeable, nonselective cation channel that is expressed highly in the brain and broadly in other tissues (Nagamine et al., 1998; Kaneko et al., 2006). TRPM2 has a Nudix box motif in the intracellular C-terminal tail and is gated by intracellular adenosine diphosphate ribose (ADPR) or structurally related molecules (Nagamine et al., 1998; Perraud et al., 2001). TRPM2 acts as a sensor for ROS/NOS such as hydrogen peroxide $\left(\mathrm{H}_{2} \mathrm{O}_{2}\right)$ through intracellular ADPR-dependent and ADPR-independent mecha- 
nisms (Hara et al., 2002; Buelow et al., 2008). Some physiological and pathophysiological roles of TRPM2 have been identified; for example, TRPM2 mediates $\mathrm{H}_{2} \mathrm{O}_{2}$-induced cell death (Hara et al., 2002; Kaneko et al., 2006) and insulin secretion from pancreatic $\beta$-cells (Togashi et al., 2006). TRPM2 is also expressed abundantly in immune cells, including monocytes/macrophages, neutrophils, T-lymphocytes, and microglia (Perraud et al., 2001; Sano et al., 2001; Kraft et al., 2004). A recent study showed that the treatment of monocytes with lipopolysaccharide (LPS) increases TRPM2 expression and ADPR-induced currents (Wehrhahn et al., 2010). Furthermore, TRPM2-mediated $\mathrm{Ca}^{2+}$ influx in monocytes induces the production of proinflammatory cytokines/chemokines and the infiltration of neutrophils, which contribute to the exacerbation of inflammation in the mouse colitis model (Yamamoto et al., 2008; Wehrhahn et al., 2010). These findings suggest that TRPM2 expressed in monocytic lineage cells plays an important role in the aggravation of inflammatory processes.

An important question is whether TRPM2 is involved in pathological pain that is based on neuroinflammation-mediated peripheral and central sensitization of the pain-signaling pathway. Here we demonstrate that TRPM2 plays an important role in inflammatory and neuropathic pain using TRPM2 knock-out (TRPM2-KO) mice. The effects of TRPM2 deficiency on the pronociceptive inflammatory responses at peripheral and spinal sites were also examined.

\section{Materials and Methods}

\section{Animals}

All experiments were conducted in accordance with the ethical guidelines of the Kyoto University Animal Research Committee. Male mice aged 7-9 weeks were used in this study. TRPM2-KO mice were generated as reported previously (Yamamoto et al., 2008). The TRPM2-KO mouse line was backcrossed with C57BL/6J mice for seven generations to eliminate any background effects on the phenotypes. They were kept at a constant ambient temperature of $24 \pm 1^{\circ} \mathrm{C}$ under a $12 \mathrm{~h}$ light/dark cycle with free access to food and water.

\section{Pain models and behavioral tests}

Animals were acclimatized to the testing room for at least $1 \mathrm{~h}$ before all behavioral tests. The same experimenter handled and tested all animals in each experiment and was blinded to the genotype of each animal.

Von Frey filament test. Mechanical sensitivity was assessed by the updown method using calibrated von Frey filaments as described previously with slight modifications (Chaplan et al., 1994; Callahan et al., 2008). Mice were acclimatized on a metal mesh floor in small cylinders (diameter, $7.5 \mathrm{~cm}$; height, $10 \mathrm{~cm}$ ) for $2 \mathrm{~h}$. The mechanical sensitivity was evaluated using a set of eight calibrated von Frey filaments $(0.008,0.02$, $0.04,0.07,0.16,0.4,0.6,1.0$, and $1.4 \mathrm{~g}$; Stoelting) that were applied to the plantar surface of the hindpaw until the filament bent slightly for a few seconds. A withdrawal reflex of the hindpaw during stimulation or immediately after stimulus removal was considered a positive response. The first stimulus was always the $0.16 \mathrm{~g}$ filament. When there was a positive response, the next lower filament was applied, and when there was no response, the next higher filament was used. After the first change in responses, four additional responses were observed, and the $50 \%$ paw withdrawal threshold value was calculated (Dixon, 1980; Chaplan et al., 1994). When a positive response to a stimulus with the $0.008 \mathrm{~g}$ filament or a negative response to a stimulus with the $1.4 \mathrm{~g}$ filament was observed, the value of 0.008 or $1.4 \mathrm{~g}$ was assigned, respectively.

Hargreaves test. Thermal sensitivity of the paw was assessed with the Hargreaves radiant heat apparatus (Ugo Basile) as described previously (Hargreaves et al., 1988). Mice were acclimatized on a glass floor in small Plexiglas cubicles (length, $9 \mathrm{~cm}$; width, $5 \mathrm{~cm}$; height, $5 \mathrm{~cm}$ ) for $2 \mathrm{~h}$, after which a light beam was focused on the midplantar of the hindpaw. The latency to respond by withdrawing the paw away from the light was recorded. The intensity of the light beam was adjusted to achieve an average baseline paw withdrawal latency of $\sim 8-10 \mathrm{~s}$ in naive mice. The cutoff time was $15 \mathrm{~s}$ to prevent tissue damage. Stimuli were applied to the paws three times at $5 \mathrm{~min}$ intervals, and the average latency was calculated.

Hot plate test. Thermal sensitivity was assessed with a hot plate analgesimeter (Ugo Basile). Mice were acclimatized to the testing apparatus for $1 \mathrm{~h}$. They then were placed individually on the center of the hot plate maintained at 52 or $55^{\circ} \mathrm{C}$ in a transparent Plexiglas cylinder. The latency to respond either by jumping or by licking or flicking the hindpaw (whichever came first) was measured to the nearest $0.1 \mathrm{~s}$. After the measurement, the mice were immediately removed from the hot plate and returned to the home cage. The cutoff time was $30 \mathrm{~s}$ to prevent tissue damage.

Formalin test. Mice were acclimatized in individual observation cages for $1 \mathrm{~h}$, after which $20 \mu \mathrm{l}$ of a $5 \%$ formalin solution was injected intraplantarly into the plantar surface of the right hindpaw. The duration of licking and biting behaviors was recorded every $5 \mathrm{~min}$ for $60 \mathrm{~min}$ after formalin injection. The acute phase, which lasted up to about $10 \mathrm{~min}$ after formalin injection, was defined as the first phase $(0-10 \mathrm{~min}$ postinjection). The persistent inflammatory phase, which started after $10 \mathrm{~min}$ and persisted up to $60 \mathrm{~min}$ after injection, was defined as the second phase (10-60 min postinjection).

Carrageenan-induced inflammatory pain. Unilateral inflammation was induced by intraplantar injection with $20 \mu \mathrm{l}$ of a $3 \%$ solution of $\lambda$-carrageenan (Sigma-Aldrich) dissolved in physiological saline into the plantar surface of the right hindpaw. The paw volume was measured with a plethysmometer (Ugo Basile) before and after injection.

Partial sciatic nerve ligation and spinal nerve transection models of neuropathic pain. For the partial sciatic nerve ligation ( $\mathrm{pSNL}$ ) model of neuropathic pain, the surgery was performed as described previously with slight modifications (Seltzer et al., 1990; Malmberg and Basbaum, 1998). Briefly, under sodium pentobarbital anesthesia, a $5 \mathrm{~mm}$ incision was made, and the right sciatic nerve was exposed just distal to the branch leading to the posterior biceps femoris/semitendinous muscles. The onethird to one-half diameter of the right sciatic nerve at the upper thigh level was ligated tightly with a 9-0 silk suture. The wound was closed by suturing the muscle and skin layers.

For the spinal nerve transection (SNT) model of neuropathic pain, the surgery was performed as described previously with slight modifications (Kim and Chung, 1992; DeLeo et al., 2000). Briefly, under sodium pentobarbital anesthesia, a $1.5 \mathrm{~cm}$ longitudinal incision overlying the L3-L6 section was made. The left paraspinal muscles were separated from the superior articular processes and the transverse processes to expose the L3 and L4 spinal nerves. The L4 spinal nerve was transected without damaging the $\mathrm{L} 3$ spinal nerve. The wound was closed by suturing the muscle and skin layers.

\section{Immunohistochemistry}

Mice were deeply anesthetized with sodium pentobarbital and perfused through the ascending aorta with saline, followed by $4 \%$ paraformaldehyde. The planter tissue, sciatic nerve, and spinal cord were removed, postfixed for $3 \mathrm{~h}$, and cryoprotected overnight at $4^{\circ} \mathrm{C}$ in $20 \%$ sucrose. The tissues were frozen and sectioned with a cryostat (Leica). The sections (20 $\mu \mathrm{m}$ ) were then incubated with the primary antibodies for F4/80 (rat anti-F4/80 antibody, 1:200; Santa Cruz Biotechnology), Gr-1 (rat antiGr-1/Ly-6G antibody, 1:500; R \& D Systems), Iba-1 (rabbit anti-Iba-1 antibody, 1:1000; Wako Pure Chemical Industries), CD11b (rat antiCD11b antibody, 1:1000; Serotec), or phosphorylated-p38 (p-p38, rabbit anti-phospho-p38 MAPK, 1:500; Cell Signaling Technology) at $4^{\circ} \mathrm{C}$ overnight. Sections then were labeled with fluorescence-labeled secondary antibodies (Alexa Fluor 594- or 488-labeled donkey anti-rat IgG, Alexa Fluor 594- or 488-labeled donkey anti-rabbit IgG, 1:2000; Invitrogen) at room temperature for $1 \mathrm{~h}$ in the dark. Images were captured with a confocal fluorescence microscope. F4/80- and Gr-1-positive cells were counted, and the intensity of Ibal-ummunofluorescent signal was quantified using Image J software (National Institutes of Health). 


\section{Magnetically activated cell sorting}

The inflamed plantar tissue was removed from carrageenan-induced inflammatory pain model mice, and spinal cord (L3-L5) was extirpated from $\mathrm{pSNL}$-induced neuropathic pain mice. Six paws were pooled and were digested for $1 \mathrm{~h}$ at $37^{\circ} \mathrm{C}$ with HBSS containing $3 \mathrm{mg} / \mathrm{ml}$ collagenase and $1 \mathrm{mg} / \mathrm{ml}$ hyaluronidase (Sigma) as described previously, with slight modifications (Rittner et al., 2001). Three L3-L5 spinal cords were pooled and dissociated to single-cell suspension using neural tissue dissociation kit (Miltenyi Biotec) according to the manufacturer's protocol. Cells were pressed through a $40 \mu \mathrm{m}$ nylon filter (BD Biosciences) to remove particles. Cells were incubated with phycoerythrin (PE)-labeled rat anti-CD11b antibody (BD Biosciences) for microglia, PE-labeled rat anti-F4/80 antibody (Biolegend) for macrophages, or biotin-labeled rat anti-Gr-1 antibody (Miltenyi Biotec) for neutrophils, and followed with magnetically labeled anti-PE MicroBeads (Miltenyi Biotec) or antibiotin MicroBeads. The cell suspension was loaded onto a magnetically activated cell sorting (MACS) column (Miltenyi Biotec) in the magnetic field, and then CD11b-, F4/80-, or Gr-1-positive cells were isolated.

\section{Real-time PCR}

The inflamed plantar tissue was removed from carrageenan-induced inflammatory pain model mice. The injured sciatic nerve, which was cut 3 $\mathrm{mm}$ on either side of the ligation sites, was extirpated from pSNLinduced neuropathic pain mice. The plantar tissue and the sciatic nerve were homogenized with a Polytron homogenizer and a MicroSmash (TOMY Seiko), respectively, in RLT buffer (RNeasy Micro Kit; Qiagen). Total RNA from the tissues and cells was isolated with the RNeasy Micro kit (Qiagen), and cDNA was synthesized with the SuperScriptIII Firststrand SuperMix (Invitrogen), in accordance with the manufacturers' suggested protocols. The quantitative measurements of the TRPM2, CCL2, TNF- $\alpha$, and GAPDH mRNA expression levels were performed using the TaqMan Universal PCR Master Mix (Applied Biosystems) and TaqMan Gene Expression Assays reagent (mouse TRPM2, Mm00663098_m1; mouse CCL2, Mm00441242_ml; mouse TNF- $\alpha$, Mm00443258_ml; mouse GAPDH, Mm99999915_g1; Applied Biosystems).

Each PCR amplification consisted of heat activation for $10 \mathrm{~min}$ at $95^{\circ} \mathrm{C}$ followed by 40 cycles of $95^{\circ} \mathrm{C}$ for $10 \mathrm{~s}$ and $60^{\circ} \mathrm{C}$ for $1 \mathrm{~min}$. The quantitative measurements of inducible nitric oxide (NO) synthase (iNOS), chemokine (C-X-C motif) ligand-2 (CXCL2), IL-1 $\beta$, IL-6, and $\beta$-actin mRNA expression levels were performed using a Light Cycler 480 SYBR Green I Master (Roche) and the oligonucleotide primers (iNOS, 5'AGAAGGGGACGAACTCAGTG- $3^{\prime}$ and $5^{\prime}$-GCTTCGGACATCAAAGG TCT-3'; CXCL2, 5' -AAAATCATCCAAAAGATACTGAACAA-3' and 5'-CTTTGGTTCTTCCGTTGAGG-3'; IL-1 $\beta$, $5^{\prime}$-TGAGCACTTCTTTT CCTTCA- $3^{\prime}$ and $5^{\prime}$-TTGTCTAATGGGAACGTCACAC- ${ }^{\prime}$; IL-6, 5' ${ }^{\prime}$-TC TAATTCATATCTTCAACCAAGAGG- $3^{\prime}$ and $5^{\prime}$-TGGTCCTTAGCCAC TCCTTC- $3^{\prime} ; \beta$-actin, $5^{\prime}$-ACTGGGACGACATGGAGAAG- ${ }^{\prime}$ and $5^{\prime}$-GA GGCATACAGGGACAGCA-3'). Each PCR amplification consisted of heat activation for $5 \mathrm{~min}$ at $95^{\circ} \mathrm{C}$, followed by 60 cycles of $95^{\circ} \mathrm{C}$ for $10 \mathrm{~s}$, $58^{\circ} \mathrm{C}$ for $30 \mathrm{~s}$, and $72^{\circ} \mathrm{C}$ for $1 \mathrm{~min}$. Three separate experiments were performed, and every sample was assayed in duplicate in the same plate. Measurement of the GAPDH or $\beta$-actin level of the samples was used to normalize mRNA contents. Each mRNA level was expressed relative to the corresponding control.

\section{Measurement of $\mathrm{H}_{2} \mathrm{O}_{2}$ content}

The plantar tissues were removed from the mouse hindpaw, frozen in liquid nitrogen, and stored at $-80^{\circ} \mathrm{C}$ until use. They were homogenized with a Polytron homogenizer in ice-cold $50 \mathrm{~mm}$ phosphate buffer, $\mathrm{pH}$ 7.4 , with $0.5 \%$ hexadecyltrimethylammonium bromide. The homogenates were centrifuged at $15,000 \mathrm{rpm}$ at $4^{\circ} \mathrm{C}$ for $10 \mathrm{~min}$ to remove debris. The supernatants were filtered through an Amicon Ultra centrifugal filter unit with an Ultracel-100 membrane (Millipore) by centrifugation at $15,000 \mathrm{rpm}$ at $4^{\circ} \mathrm{C}$ for $10 \mathrm{~min}$. The $\mathrm{H}_{2} \mathrm{O}_{2}$ content in the flowthrough was determined with an Amplex Red Assay Kit (Invitrogen) in accordance with the manufacturer's protocol.

\section{Measurement of myeloperoxidase activity}

The plantar tissues were removed from the mouse hindpaw, frozen in liquid nitrogen, and stored at $-80^{\circ} \mathrm{C}$ until use. They were homogenized with a Polytron homogenizer in ice-cold $50 \mathrm{~mm}$ phosphate buffer, $\mathrm{pH}$ 7.4 , with $0.5 \%$ hexadecyltrimethylammonium bromide. The homogenates were centrifuged at $15,000 \mathrm{rpm}$ at $4^{\circ} \mathrm{C}$ for $10 \mathrm{~min}$ to remove debris. The activity of neutrophil-specific enzyme myeloperoxidase (MPO) in the supernatants was determined as an indication of neutrophil accumulation with a Myeloperoxidase Chlorination Assay Kit (Cayman Chemical), in accordance with the manufacturer's protocol.

\section{ELISA}

The plantar tissues and the sciatic nerves were homogenized with a Polytron homogenizer and a MicroSmash (TOMY Seiko), respectively, in ice-cold homogenizing buffer (PBS containing $0.1 \%$ Triton X-100 and $1 \%$ protease-inhibitor mixture). The homogenates were centrifuged to remove debris, and protein concentrations in the supernatants were measured using DC protein assay reagents (Bio-Rad). The tissue homogenates and culture media that were suspected to have higher cytokine/ chemokine levels than the linear range of the standard curve were diluted appropriately with the homogenizing buffer and fresh culture media, respectively. The CXCL2, CCL2, and TNF- $\alpha$ levels in the tissue homogenates and the culture media were determined using mouse CXCL2, CCL2, and TNF- $\alpha$ ELISA kits (R \& D Systems), in accordance with the manufacturer's protocols. Every sample was assayed in duplicate in the same plate.

\section{Preparation of cultured peritoneal macrophages}

Mice (7-9 weeks) were injected intraperitoneally with $1 \mathrm{ml}$ of $4 \%$ thioglycolate (Difco Laboratories). After $3 \mathrm{~d}$, mice were killed and peritoneal macrophages were collected by washing the peritoneal cavity with $4 \mathrm{ml}$ of ice-cold PBS. The macrophages were seeded onto plastic plates in DMEM (Sigma-Aldrich) supplemented with $10 \%$ (v/v) heat-inactivated fetal bovine serum (FBS). After incubation at $37^{\circ} \mathrm{C}$ for $24 \mathrm{~h}$, nonadherent cells were removed by repeated washing. More than $95 \%$ of the adherent cells were macrophages, as identified by May-Grüwald/Giemsa staining. The culture medium was replaced with fresh medium containing 100 $\mathrm{ng} / \mathrm{ml}$ LPS and $10 \mathrm{ng} / \mathrm{ml}$ interferon (IFN) $-\gamma$, and the cells were then incubated at $37^{\circ} \mathrm{C}$ for the indicated time. The culture media were collected and stored at $-80^{\circ} \mathrm{C}$ until use. The cells were washed twice with PBS and scraped with a cell scraper in RLT buffer (RNeasy Micro Kit; Qiagen) for the quantification of the mRNA expression level. For intraplantar injection, cultured peritoneal macrophages derived from wildtype (WT) and TRPM2-KO mice were suspended in PBS after LPS (100 $\mathrm{ng} / \mathrm{ml}$ ) stimulation. A single intraplantar injection of $20 \mu \mathrm{l}$ of peritoneal macrophages $\left(5 \times 10^{5}\right.$ cells $)$ was given to the left hindpaw of naive WT mice.

\section{Preparation of primary cultured microglia}

Primary cultured microglia were prepared from newborn WT and TRPM2-KO mice as described previously (Ikeda-Matsuo et al., 2005). Briefly, mice at postnatal day 1 were anesthetized by hypothermia, and the brains were removed from the skull and minced. Tissue fragments were incubated at $37^{\circ} \mathrm{C}$ for $15 \mathrm{~min}$ in $0.25 \%$ trypsin (Nacalai Tesque) containing $0.1 \mathrm{mg} / \mathrm{ml}$ bovine pancreatic DNase (Sigma-Aldrich). Following centrifugation at $1700 \mathrm{rpm}$ for $5 \mathrm{~min}$, the supernatant was discarded, and the pellet was resuspended in DMEM (D5796; Invitrogen) supplemented with $10 \%$ FBS, $5 \mu \mathrm{g} / \mathrm{ml}$ insulin (Sigma-Aldrich), and $1 \%$ anti-biotic-anti-mycotic solution (Nacalai Tesque). Dissociated cells were seeded on $75 \mathrm{~cm}^{2}$ flasks and maintained at $37^{\circ} \mathrm{C}$ in a humidified $5 \%$ $\mathrm{CO}_{2}$ atmosphere. The medium was changed after $2 \mathrm{~d}$ and then every 3 or 4 d. After 2-3 weeks, the primary mixed glial cultures in flasks were shaken for $90 \mathrm{~min}$ at $150 \mathrm{rpm}$. The detached cells were plated on plastic dishes.

\section{Measurement of NO accumulation from microglia}

The NO production was analyzed by measuring the accumulated level of its stable metabolite (nitrite) in the microglial culture supernatants with the Griess reaction. For this assay, cells were grown in 48 -well plates. The amount of NO released during treatment with LPS/IFN- $\gamma$ was quantified as the concentration of nitrite in the culture medium. In brief, $50 \mu \mathrm{l}$ of culture supernatants after LPS/IFN- $\gamma$ treatment were added to 96 -well plates and mixed with an equal volume of Griess reagent (1\% sulfanil- 
amide, $2.5 \%$ phosphoric acid, and $0.1 \%$ naphthylethlenediamine dihydrochloride) for 10 min at room temperature. Absorbance of the diazonium compound was measured at 540 $\mathrm{nm}$ using a microplate reader (Model 680; BioRad Laboratories). Absolute levels of nitrite were determined with reference to a standard curve obtained from defined concentrations of sodium nitrite (Sigma-Aldrich).

\section{Statistical analysis}

Data are presented as means \pm SEM and were analyzed using GraphPad Prism. Statistical analyses of the $50 \%$ withdrawal thresholds were performed using Mann-Whitney $U$ tests at individual time points. To analyze other behavioral responses, including the formalin test, thermal hyperalgesia, and paw edema, twoway repeated measures ANOVA was used, with comparisons between groups at individual time points made with the unpaired $t$ test. The production of $\mathrm{H}_{2} \mathrm{O}_{2}$ and cytokine/chemokine and MPO activity were analyzed by two-way ANOVA, followed by Bonferroni's post hoc comparison test. The temporal changes in the TRPM2 mRNA expression were analyzed by two-way ANOVA, followed by Dunnett's post hoc comparison test. Differences between two groups were compared with the unpaired $t$ test. In all cases, differences of $p<0.05$ were considered statistically significant.

\section{Results}

Nocifensive behaviors to mechanical, thermal, and chemical stimuli in TRPM2-KO mice

To assess whether TRPM2 deficiency alters physiological pain, we compared nocifensive responses of WT and TRPM2-KO mice to acute mechanical and thermal stimuli. In the von Frey filament test, there was no difference in the $50 \%$ withdrawal threshold of the hindpaw to mechanical stimulation between WT and TRPM2-KO mice (Fig. 1A). The Hargreaves test and the hot plate test revealed no differences in the thermal nociceptive latency to a light beam or a hot plate at 52 and $55^{\circ} \mathrm{C}$ between WT and TRPM2-KO mice (Fig. $1 B, C$ ). In the formalin test, a typical biphasic nocifensive behavioral response was observed in WT mice following an intraplantar injection of formalin. The formalininduced nocifensive behavioral responses were significantly decreased in TRPM2-KO mice (two-way ANOVA; $F_{(1,14)}=5.82$; $p<0.05)$. Although there was no difference in the behavioral responses in the first phase $(0-10 \mathrm{~min})$, the behavioral responses in second phase $(10-60 \mathrm{~min})$ were significantly decreased in TRPM2-KO mice compared with WT mice (Fig. $1 D, E$ ). These data suggest that TRPM2-KO mice showed normal sensitivity to mechanical, thermal, and chemical stimuli, but weaker sensitivity to chemical stimulus-induced inflammatory pain.

\section{Roles of TRPM2 in the carrageenan-induced inflammatory pain model}

As the second phase of formalin test is recognized as acute inflammatory pain models, we analyzed the roles of TRPM2 in detail using the carrageenan-induced pain model, a widely used and reliable model for inflammatory pain. In WT mice, an intraplantar injection of carrageenan decreased the 50\% withdrawal threshold to mechanical stimuli and the nociceptive latency to thermal stimuli. In TRPM2-KO mice, the carrageenan-induced
B
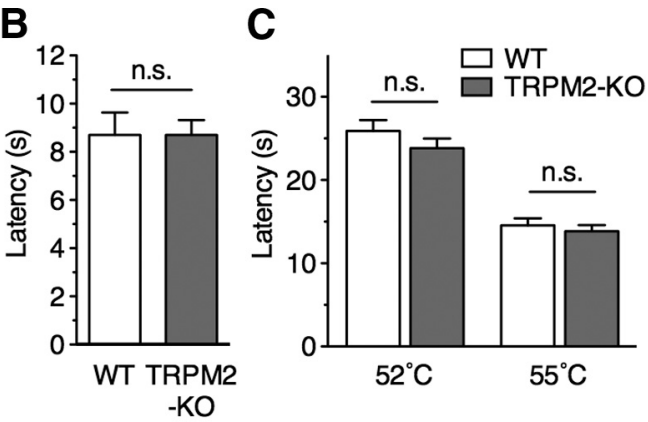

E

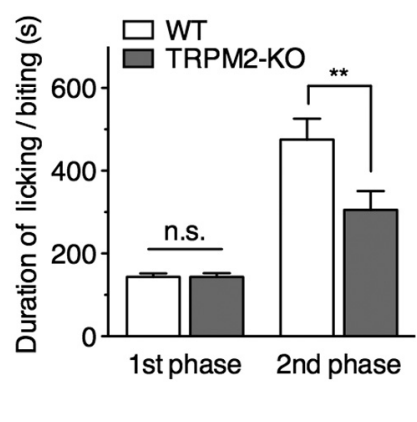

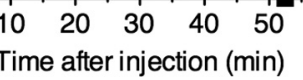

Figure 1. TRPM2-K0 mice display normal sensitivities to mechanical and thermal stimuli, but exhibit attenuated responses in the formalin tests. $\boldsymbol{A}$, In naive WT and TRPM2-K0 mice, the $50 \%$ withdrawal thresholds to mechanical stimuli 列 of the behaviors for $0-10 \mathrm{~min}$ (first phase) and 10-60 min (second phase) after the injection. ${ }^{* *} p<0.01(n=$ \pm SEM. n.s., Not significant.

mechanical allodynia $\left(F_{(1,14)}=62.93 ; p<0.001\right)$, thermal hyperalgesia $\left(F_{(1,10)}=6.53 ; p<0.05\right)$, and paw edema $\left(F_{(1,14)}=9.53\right.$; $p<0.001)$ were attenuated significantly compared with WT mice (Fig. $2 A-C$ ). In the carrageenan-inflamed paws of WT and TRPM2-KO mice, the tissue content of $\mathrm{H}_{2} \mathrm{O}_{2}$, an endogenous stimulator of TRPM2, was significantly increased at $4 \mathrm{~h}$ after carrageenan injection compared with that in the saline-injected paws $\left(F_{(1,10)}=14.43 ; p<0.001\right)$. There was no difference between WT and TRPM2-KO mice $\left(F_{(1,10)}=0.46 ; p=0.513\right.$; Fig. $2 D)$. The TRPM2 mRNA expression level in the carrageenaninflamed paws was significantly upregulated at 8 and $24 \mathrm{~h}$ after carrageenan injection (Fig. 2E). Cell identification using MACS with antibodies for the macrophage-specific marker F4/80 and the neutrophil-specific marker Gr-1 revealed that TRPM2 mRNA was expressed in macrophages and neutrophils isolated from the paws. The accumulation of macrophages and neutrophils expressing TRPM2 mRNA is responsible for the upregulation of TRPM2 mRNA in the carrageenan-inflamed paws (Fig. $2 F, G)$.

Then, we compared the numbers of macrophages and neutrophils in the carrageenan-inflamed paws of WT and TRPM2-KO mice by immunofluorescence staining. In WT mice, the numbers of F4/80-positive cells and Gr-1-positive cells kept increasing at 4, 8 and $24 \mathrm{~h}$ after carrageenan injection. There was no difference in the number of F4/80-positive cells between WT and TRPM2-KO mice $\left(F_{(1,4)}=0.26, p=0.634\right.$; Fig. $\left.3 A, C\right)$. In contrast, the number of Gr-1-positive cells was reduced significantly $\left(F_{(1,4)}=9.44\right.$, $p<0.05)$ at $8 \mathrm{~h}$ after injection in TRPM2-KO mice, while the significant reduction was disappeared at $24 \mathrm{~h}$ (Fig. $3 B, D$ ). As another indication of neutrophil accumulation, the activity of MPO, a neutrophil-specific enzyme, was measured in the inflamed paws. MPO activity kept increasing at 4 and $8 \mathrm{~h}$ after 

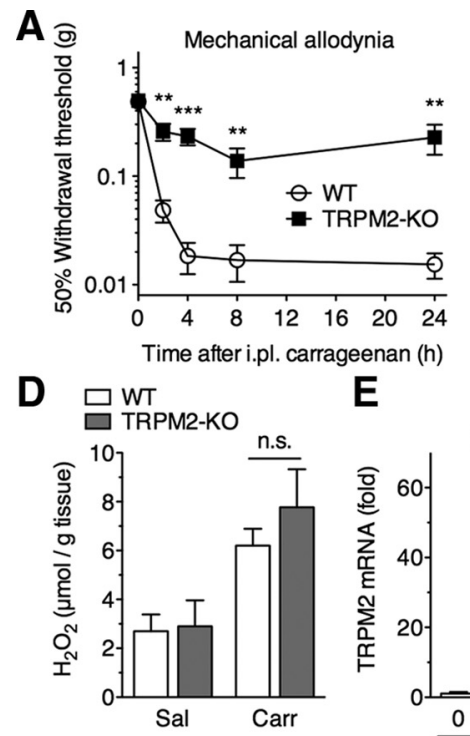

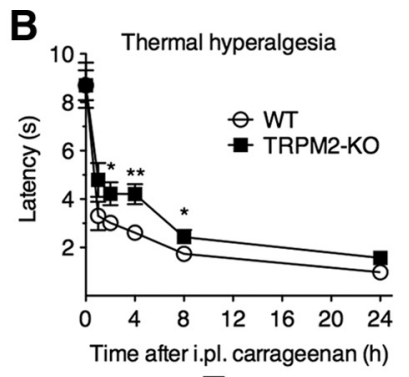

$\mathbf{F}$
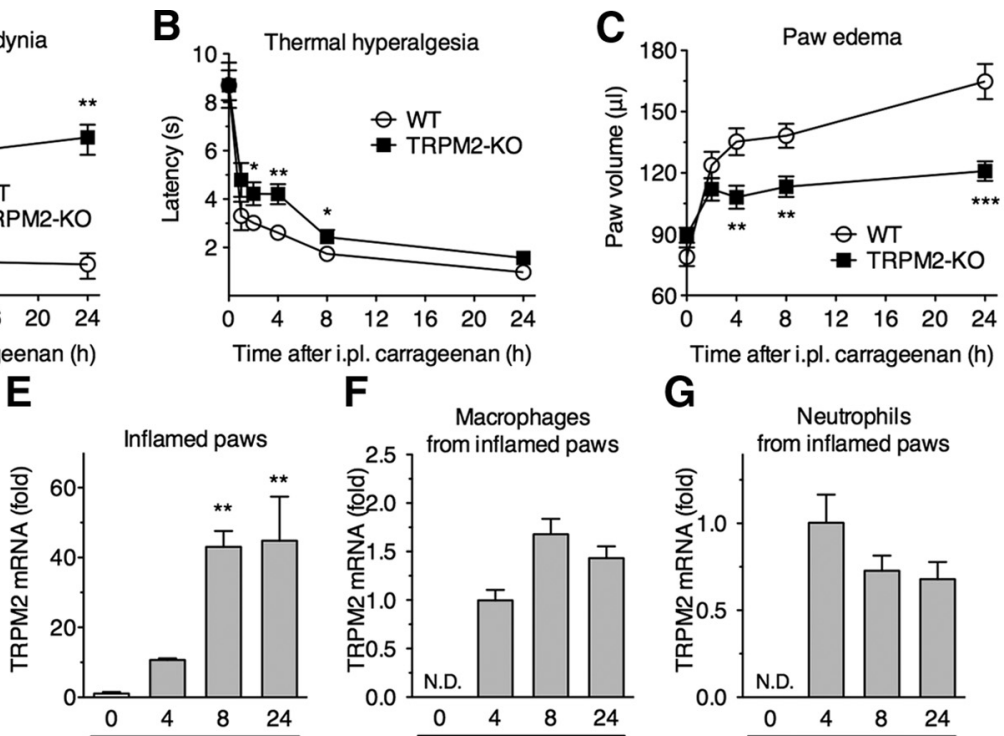

Time after i.pl. carrageenan (h) Time after i.pl. carrageenan (h) Time after i.pl. carrageenan (h)

Figure 2. TRPM2 deficiency impairs carrageenan-induced inflammatory pain. WT and TRPM2-K0 mice were injected intraplantarly with carrageenan. $A-C$, The $50 \%$ withdrawal threshold to mechanical stimulation in the von Frey filament test $(n=8 ; A)$, latency to thermal stimuli in the Hargreaves test $(n=6 ; \boldsymbol{B})$, and paw edema $(n=8 ; \boldsymbol{C})$ were determined at the indicated times. ${ }^{*} p<0.05 ;{ }^{* *} p<0.01$; ${ }^{* * *} p<0.001$ (compared with WT mice). D, The $\mathrm{H}_{2} \mathrm{O}_{2}$ content in the paws of WT and TRPM2-KO mice was measured 4 h after the injection of saline (Sal) or carrageenan (Carr). n.s., Not significant. $n=3-4$. $E$, Expression level of TRPM2 mRNA in the carrageenan-inflamed paws of WT mice was measured by real-time PCR at the indicated times. TRPM2 mRNA level was normalized to the GAPDH $\mathrm{mRNA}$ level and expressed relative to the control (fold). ${ }^{* *} p<0.01$ (compared with noninjected control paws); $n=3 . \boldsymbol{F}, \mathbf{G}$, Expression levels of TRPM2 mRNA weremeasured in F4/80-positive macrophages $(\boldsymbol{F})$ and Gr-1-positive neutrophils $(\boldsymbol{G})$ isolated from the carrageenan-inflamed paw by MACS. The TRPM2 mRNA level was normalized to the GAPDH mRNA level and expressed relative to the samples $4 \mathrm{~h}$ after the carrageenan injection, because macrophages and neutrophils could not be isolated from the noninjected control paws. N.D., Not determined. $n=4$.

A

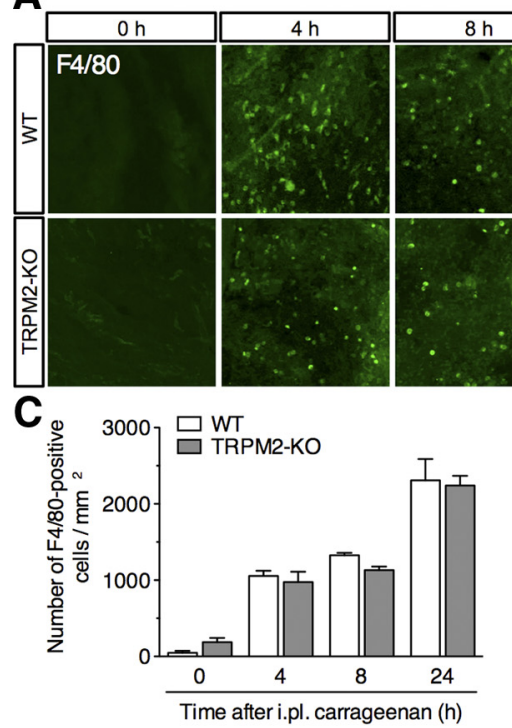

$\mathbf{F}$

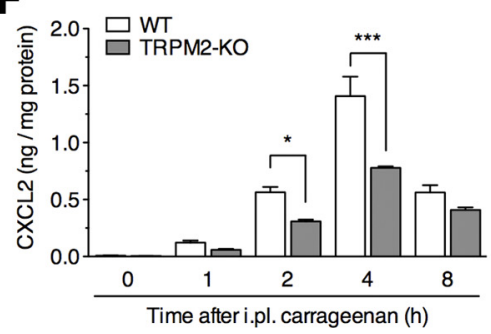

B

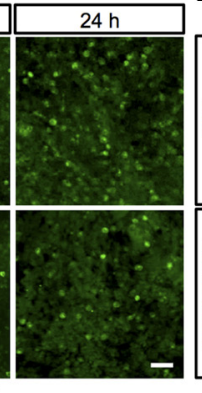

D

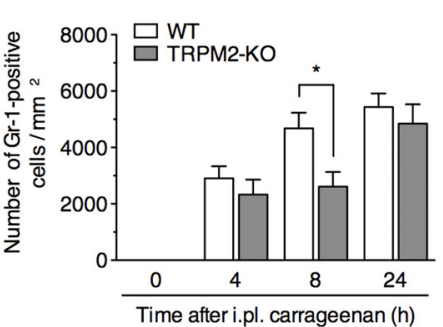

G

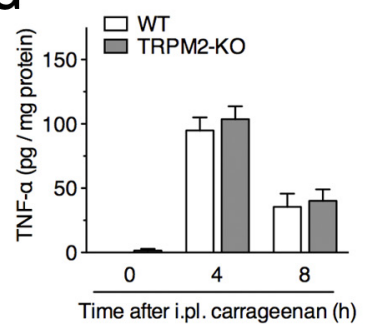

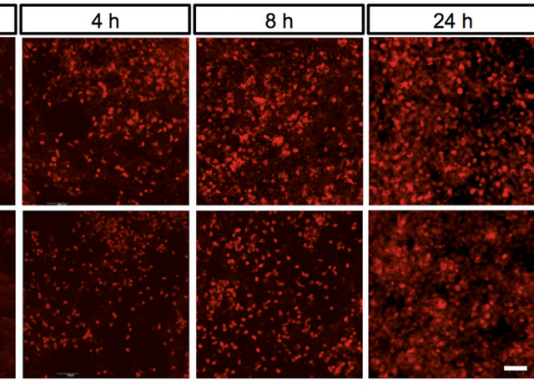

$\mathbf{E}$
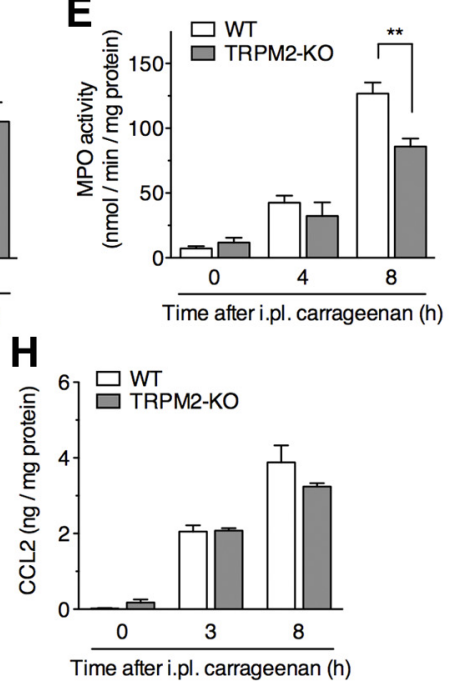

Figure 3. TRPM2 deficiency impairs some carrageenan-induced pronociceptive inflammatory responses in the inflamed paws. WT and TRPM2-K0 mice were injected intraplantarly with $20 \mu \mathrm{l}$ of $3 \% \lambda$-carrageenan solution. $\boldsymbol{A}-\boldsymbol{D}$, Sections of carrageenan-inflamed paws of WT and TRPM2-K0 mice were immunostained with a macrophage-specific marker, $F 4 / 80$ antibody (green; $A$ ), and a neutrophil-specific marker, Gr-1 antibody (red; $\boldsymbol{B})$, at 4, 8, and $24 \mathrm{~h}$ after the carrageenan injection. Scale bars: $50 \mu \mathrm{m}$. The numbers of F4/80-positive cells $(\boldsymbol{C})$ and $\mathrm{Gr}-1$-positive cells $(\boldsymbol{D})$ in the sections were counted $(n=3)$. $\boldsymbol{E}$, MPO activities in the carrageenan-inflamed paws of WT and TRPM2-KO mice were measured at the indicated times $(n=4)$. $\boldsymbol{F}-\boldsymbol{H}$, In the carrageenan-inflamed paws of WT and TRPM2-KO mice, the levels of $\mathrm{CXCL2}(\boldsymbol{F})$, TNF- $\alpha(\boldsymbol{G})$, and $C \mathrm{CL} 2(\boldsymbol{H})$ were measured by ELISA. ${ }^{*} p<0.05 ;{ }^{* *} p<0.01 ;{ }^{* * *} p<0.001 ; n=3-4$. Data are expressed as means \pm SEM. 
carrageenan injection in WT mice. The activity in TRPM2-KO mice was significantly lower than WT mice at $8 \mathrm{~h}$ after injection $\left(F_{(1,6)}=19.94, p<0.01\right.$; Fig. $3 E)$. These data indicate that neutrophil infiltration, but not macrophage recruitment, is reduced in the carrageenaninflamed paw of TRPM2-KO mice. In WT mice, carrageenan injection markedly increased the production of CXCL2 (also named macrophage inflammatory protein 2) in the inflamed-paws, with maximal production at $4 \mathrm{~h}$, while CXCL1 (also named keratinocyte-derived chemokine) was not detected. In TRPM2-KO mice, the CXCL2 production was decreased significantly at 2 and $4 \mathrm{~h}$ after carrageenan injection $\left(F_{(1,6)}=61.55, p<0.001\right.$; Fig. $3 F)$. In contrast, there were no differences in the production of the potent inflammatory cytokine TNF- $\alpha\left(F_{(1,6)}=0.52 ; p=\right.$ $0.497)$ or the major chemokine CCL2 (also named monocyte chemotactic protein-1; $\left.F_{(1,4)}=0.50, p<0.519\right)$ between WT and TRPM2-KO mice (Fig. 3G,H). These data suggest that TRPM2 deficiency reduces the production of CXCL2, which has potent chemotactic activity for neutrophils (Tekamp-Olson et al., 1990; Kielian et al., 2001; Armstrong et al., 2004), but not pronociceptive cytokine and chemokine.

\section{Roles of TRPM2 in the macrophage-mediated inflammatory responses and pain}

To determine whether macrophage TRPM2 is involved in inflammatory responses and pain, we isolated peritoneal macrophages from WT and TRPM2-KO mice and compared the ability to produce CXCL2 and mechanical allodynia. Treatment of WT macrophages with LPS/IFN- $\gamma$ for 8 or 24 h significantly upregulated TRPM2 mRNA expression compared with the level in unstimulated macrophages (Fig. 4A). Treatment of WT macrophages with LPS/IFN- $\gamma$ for 1 and $4 \mathrm{~h}$ increased CXCL2 production, while it was significantly decreased in TRPM2-KO macrophages $\left(F_{(1,12)}=7.69, p<0.05\right.$; Fig. $\left.4 B\right)$. When LPSstimulated WT macrophages were injected intraplantarly to naive WT mice, the $50 \%$ withdrawal threshold to mechanical stimuli was decreased, reaching a peak at $4 \mathrm{~h}$. The mechanical allodynia evoked by LPS-stimulated TRPM2-KO macrophages was significantly weaker than that by WT macrophages $\left(F_{(1,8)}=\right.$ 7.92, $p<0.05$; Fig. $4 C$ ). These data suggest that TRPM2 upregulated in macrophages contributes to the generation of mechanical allodynia probably through CXCL2 production. As some inflammatory cytokines, such as TNF- $\alpha$, and ROS produced from activated macrophages and other immune cells play an important role in inflammatory pain (Wang et al., 2004; Scholz and Woolf, 2007; Ren and Dubner, 2010), we determined whether TRPM2 is involved in TNF- $\alpha$ - or ROS-evoked hypersensitivity. However, the mechanical allodynia evoked by an intraplantar injection of TNF- $\alpha$ (50 pmol) or an ROS donor, tert-butyl hydroperoxide (t-BOOH; $3 \mu \mathrm{mol}$ ), was not different between WT and TRPM2-KO mice (Fig. 4D,E).
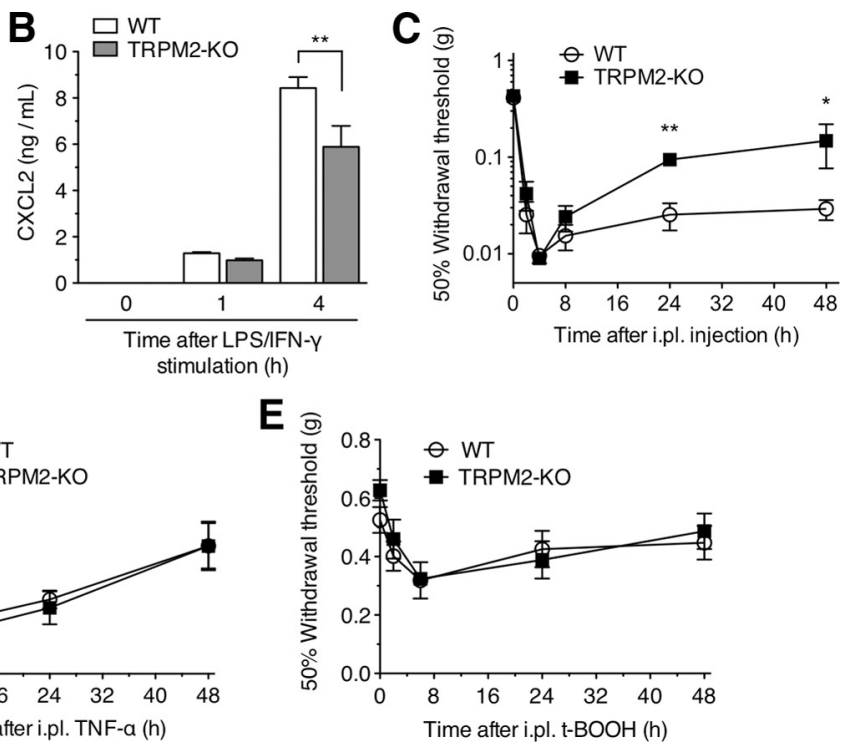

Time after i.pl. t-BOOH (h)

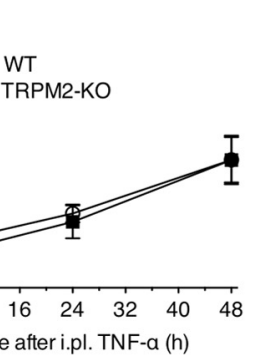

4. Upregulation of TRPM2 and production of $X X C L 2$ in cultured macrophages that evoked mechanical allodynia afte

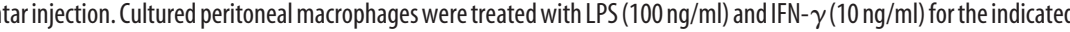

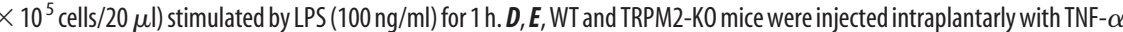
(50 in the von Frey filament test was determined at the indicated times $(n=5) .{ }^{*} p<0.05 ;{ }^{* *} p<0.01$ (compared with WT-derived are expressed as means \pm SEM.

\section{Roles of TRPM2 in peripheral nerve injury-induced neuropathic pain models}

Injury to the peripheral nerve often results in long-lasting pathological pain that is generally referred to as neuropathic pain. A growing body of evidence suggests that neuropathic pain is caused by neuroinflammation-mediated peripheral and central sensitization (Scholz and Woolf, 2007; Gao and Ji, 2010; Ren and Dubner, 2010). We analyzed the roles of TRPM2 in the peripheral nerve injury-induced neuropathic pain models. In WT mice, pSNL decreased the 50\% withdrawal threshold to mechanical stimulation and the nociceptive latency to thermal stimulation in the ipsilateral paw. In TRPM2-KO mice, pSNL-induced mechanical allodynia $\left(F_{(3,28)}=102.6 ; p<0.001\right)$ and thermal hyperalgesia $\left(F_{(3,30)}=6.22 ; p<0.001\right)$ were significantly attenuated compared with WT mice (Fig. $5 A, B$ ).

We investigated the roles of TRPM2 in the pSNL-induced inflammatory responses around the injured sciatic nerve. The expression level of TRPM2 mRNA around the ligation site of the nerve fascicle was significantly upregulated at 8 and $24 \mathrm{~h}$ after the pSNL surgery (Fig. $5 C$ ). The pSNL remarkably increased the CXCL2 production in the injured sciatic nerve of WT mice. In TRPM2-KO mice, the CXCL2 level was significantly decreased at $24 \mathrm{~h}$ after the surgery $\left(F_{(1,44)}=4.34, p<0.05\right.$; Fig. 5D). An accumulation of F4/80-positive cells and Gr-1positive cells was observed near the ligation site of the sciatic nerve, which peaked at 7 and $1 \mathrm{~d}$, respectively, after pSNL. The number of F4/80-positive cells in the injured sciatic nerve was similar in WT and TRPM2-KO mice $\left(F_{(1,20)}=0.11, p=0.743\right.$; Fig. $5 E, G)$. In contrast, the number of $\mathrm{Gr}$-1-positive cells in TRPM2-KO mice was significantly reduced at $8 \mathrm{~h}$ after surgery compared with that in WT mice, but the reduction had disappeared at 1,7 , and $14 \mathrm{~d}\left(F_{(1,20)}=8.84, p<0.001\right.$; Fig. $\left.5 F, H\right)$. 

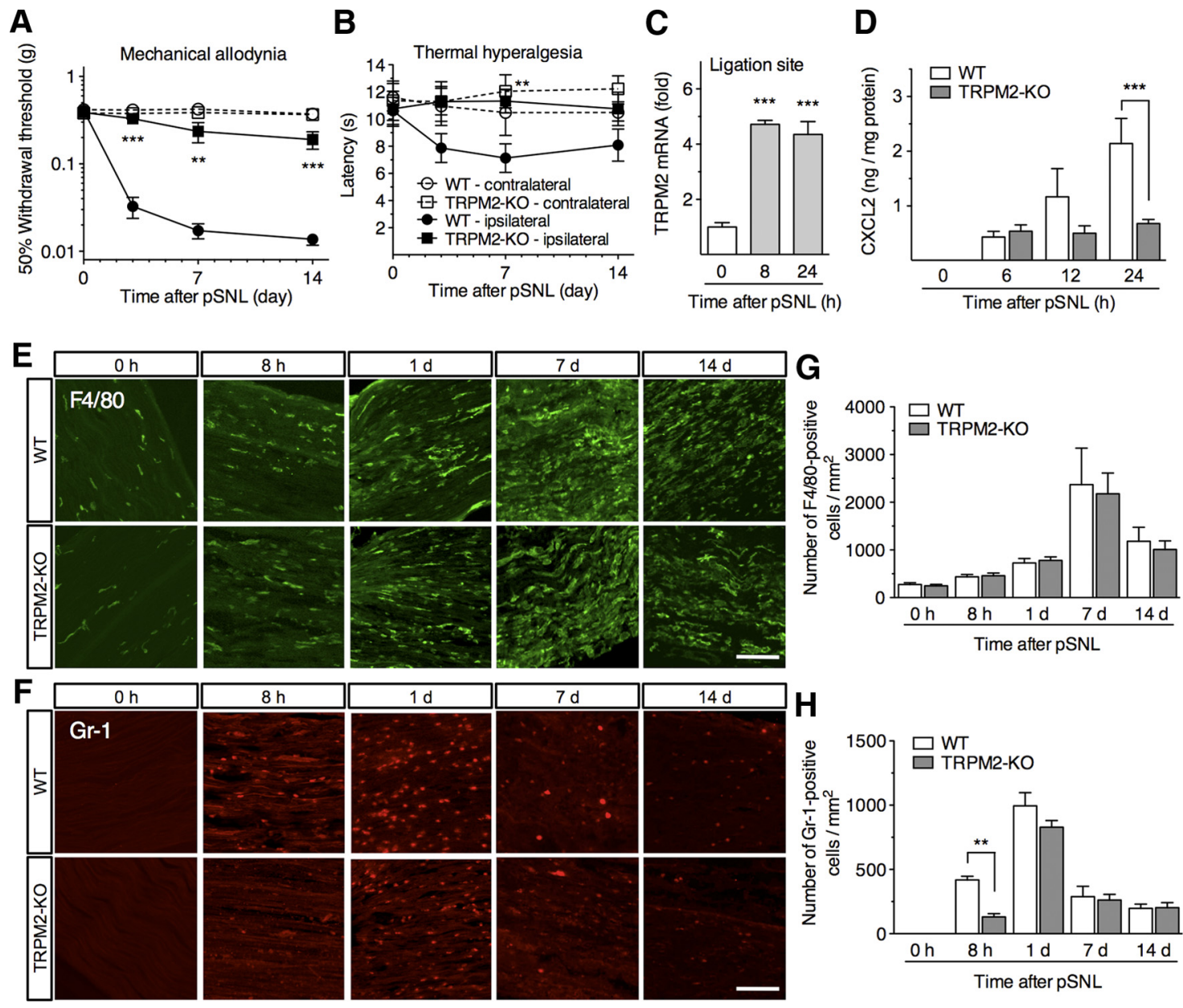

Figure 5. TRPM 2 deficiency impairs peripheral nerve injury-induced neuropathic pain and inflammatory responses in the injured sciatic nerves. $A, B$, In the pSNL model of neuropathic pain, the $50 \%$ withdrawal threshold to mechanical stimuli in the von Frey filament test $(n=8)$ and latency to thermal stimuli in the Hargreaves test $(n=8-9)$ were determined in the ipsilateral and contralateral paws of WT and TRPM2-K0 mice. ${ }^{* *} p<0.01$; ${ }^{* *} p<0.001$ (differences in the $50 \%$ withdrawal threshold of ipsilateral paws between WT and TRPM2-K0 mice). C, Expression level of TRPM2 $\mathrm{mRNA}$ in the $\mathrm{pSNL}$-injured sciatic nerves of TRPM2-KO mice was measured by real-time PCR. TRPM2 level was normalized to the GAPDH mRNA level and expressed relative to the control (fold). ${ }^{* * *} p<0.001$ (compared with nonoperated control sciatic nerves); $n=3 . \boldsymbol{D}$, In the pSNL-injured sciatic nerves of WT and TRPM2-KO mice, the CXCL2 level was measured by ELISA. $\boldsymbol{E}, \boldsymbol{F}$, Sections around the PSNL ligation site of WT and TRPM2-KO mice were immunostained with a macrophage-specific marker, F4/80 antibody (green; $\boldsymbol{E}$ ), and a neutrophil-specific marker, Gr-1 antibody (red; $\boldsymbol{F})$, at $8 \mathrm{~h}$ and 1,7 , and $14 \mathrm{~d}$ after pSNL surgery. Scale bars: $50 \mu \mathrm{m} . \mathbf{G}, \boldsymbol{H}$, The numbers of F4/80-positive cells $(\boldsymbol{G})$ and $\mathrm{Gr}-1$-positive cells $(\boldsymbol{H})$ in the sections were counted. ** $p<0.01$ $(n=3) ;{ }^{* *} p<0.001 ; n=5-11$. Data are expressed as mean \pm SEM.

In addition to peripheral neuroinflammation, spinal microglial responses to peripheral nerve injury contribute to the generation of central sensitization in neuropathic pain (Scholz and Woolf, 2007; Gao and Ji, 2010; Ren and Dubner, 2010). Since TRPM2 is expressed abundantly in microglia and mediates $\mathrm{H}_{2} \mathrm{O}_{2}$ - and ADPR-evoked $\mathrm{Ca}^{2+}$ influx (Kraft et al., 2004; Ohana et al., 2009), we determined whether TRPM2 deficiency altered the activation of spinal microglia after pSNL. As indicated by alterations in the immunofluorescence of the microglial marker Ibal and the morphology of the immunoreactive cells, pSNL robustly activated spinal microglia in the ipsilateral dorsal horn of WT mice. The intensity of Ibal immunofluorescence was increased at 3 and $7 \mathrm{~d}$, and reversed at $14 \mathrm{~d}$ after pSNL. In TRPM2-KO mice, the alteration in the immunofluorescence of Ibal was markedly suppressed, and the increases in the intensity of Ibal immunofluorescence were significantly attenuated $\left(F_{(1,16)}=14.80, p<0.01\right.$; Fig. $\left.6 A, B\right)$. In addition, pSNL increased phosphorylated p-38 signal, a marker for microglial activation, colocalized with another microglial marker, CD11b, in WT mice, whereas it was abolished in TRPM2-KO mice (Fig. 6C). Furthermore, in the CD11b-positive microglia isolated from the spinal cord of pSNL-injured WT mice by MACS, TRPM2 mRNA expression level was significantly upregulated at $3 \mathrm{~d}$ after pSNL (Fig. 6D). These results suggest that the activation of spinal microglia in parallel with TRPM2 upregulation contributes to the peripheral nerve injury-induced neuropathic pain. In another neuropathic pain model, SNT-induced mechanical allodynia was also significantly attenuated in TRPM2-KO mice compared with WT mice $\left(F_{(3,26)}=49.35, p<0.001\right.$; Fig. $\left.7 A\right)$. Similarly, the SNT-induced microglial activation in the ipsilateral dorsal horn was impaired in TRPM2-KO mice (Fig. 7B).

Finally, we examined whether TRPM2 deficiency affected on the microglial responses in vitro by using cultured microglia derived from WT or TRPM2-KO mice. Treatment of WT-derived cultured microglia with LPS/IFN- $\gamma$ for $48 \mathrm{~h}$ increased CXCL2 production and the mRNA expressions of CXCL2, TNF- $\alpha$, IL$1 \beta$, and IL- 6 . The upregulation of CXCL2 and its mRNA was impaired in the cultured microglia from TRPM2-KO mice $\left(F_{(1,13)}=118.0, p<0.0001\right.$ and $F_{(1,17)}=5.59, p<0.05$, respectively), whereas the upregulation of other proinflammatory cytokines was not altered (Fig. 8A-D). Furthermore, LPS/IFN- $\gamma$ stimulation robustly increased the expression of iNOS mRNA 
and NO release from WT microglia, whereas the increases were reduced significantly in TRPM2-KO microglia $\left(F_{(1,35)}=4.01, p<\right.$ 0.05 and $F_{(1,12)}=121.1, p<0.001$, respectively; Fig. $8 E, F)$.

\section{Discussion}

In the present study, we provide the first evidence that TRPM 2 in peripheral macrophages and spinal microglia mediates the pathogenesis of inflammatory and neuropathic pain through the aggravation of pronociceptive inflammatory responses, as supported by the following findings. (1) TRPM2 deficiency impaired inflammatory and neuropathic pain behaviors without changing basal sensitivities to mechanical and thermal stimuli. (2) Peripheral inflammation and nerve injury increased the expression of TRPM2 mRNA at the inflamed and injured sites. (3) TRPM2 deficiency impaired inflammatory responses, such as CXCL2 production, neutrophil infiltration, and spinal microglia activation, in inflammatory and neuropathic pain models. (4) The mechanical allodynia evoked by TRPM2-KO-derived macrophages was weaker than that by WT-derived macrophages. (5) Inflammatory responses were reduced in cultured macrophages and microglia derived from TRPM2-KO mice.

Recent evidence indicates that functional TRPM2 is expressed in the dorsal root ganglion neurons (Nazıroğlu et al., 2011). Although TRPM2 is expressed also in neurons in the brain and other tissues, the present findings suggest that TRPM2 plays no role in acute mechanical and thermal nociceptive pain signaling. TRPM2 deficiency had no effect on the first phase of the formalin-induced behaviors, which represents the acute chemonocifensive response due to the direct stimulation of TRPA1 on primary sensory nerves (McNamara et al., 2007). In contrast, TRPM 2 deficiency attenuated the second phase of formalin-induced behaviors, which are mainly due to inflammatory responses (Hunskaar and Hole, 1987). These results suggest that TRPM2 is involved in nocifensive behaviors mediated through inflammatory responses, but not acute chemonociceptive pain signaling.

Carrageenan-induced nociceptive responses and paw edema are associated with inflammatory cell migration and mediator production. In the current study, TRPM2 deficiency reduced neutrophil infiltration and CXCL2 production, but had no effect on macrophage recruitment. CXCL2 is a major CXC chemokine and the most potent chemoattractant for neutrophils, which is produced by monocytes and macrophages in response to various proinflammatory stimuli (Tekamp-Olson et al., 1990; Kielian et al., 2001; Armstrong et al., 2004). Activated macrophages strongly affect the subsequent activation and infiltration of neu-
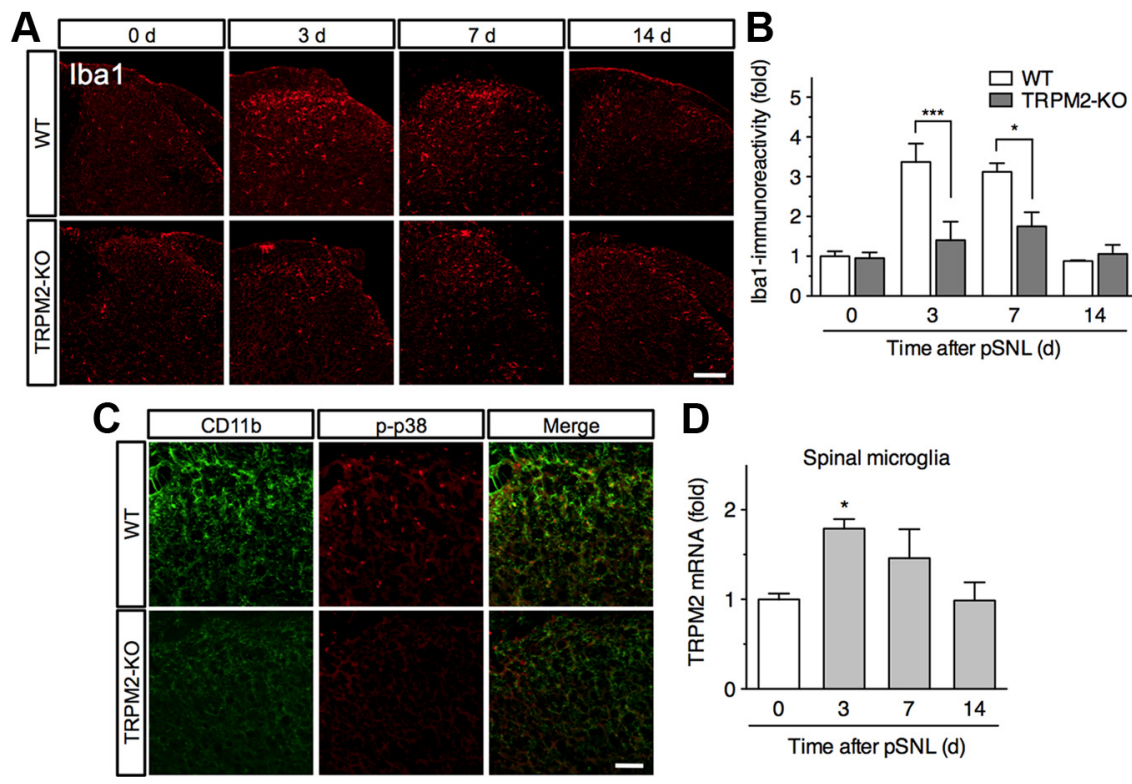

Figure 6. TRPM2 deficiency impairs the activation of spinal microglia following $p S N L$ surgery. $\boldsymbol{A}$, Sections of the L4 dorsal spinal cord of WT and TRPM2-K0 mice 3, 7, and $14 \mathrm{~d}$ after PSNL surgery were immunofluorescence stained with a microglia-specific marker, Iba1 antibody (red). $\boldsymbol{B}$, The intensity of lba1 immunoreactivity in the sections was measured and expressed relative to the nonoperated control WT mice (fold). ${ }^{*} p<0.05 ;{ }^{* *} p<0.001 ; n=3$. C, Double immunofluorescence labeling for a microgliaspecific marker, CD11b (green) and phosphorylated p-38 (p-p38; red) in the ipsilateral spinal dorsal horn of WT and TRPM2-KO mice $3 \mathrm{~d}$ after pSNL surgery. D, Expression levels of TRPM2 mRNA were measured by real-time PCR in CD11b-positive microglia isolated from the L3-L5 spinal cord of pSNL-injured WT mice by MACS. The TRPM2 mRNA level was normalized to the GAPDH mRNA level and expressed relative to the nonoperated control mice (fold). ${ }^{*} p<0.05$ (compared with control, $0 \mathrm{~d}$ ); $n=4$. Data are expressed as means \pm SEM.. Scale bars: $50 \mu \mathrm{m}$.
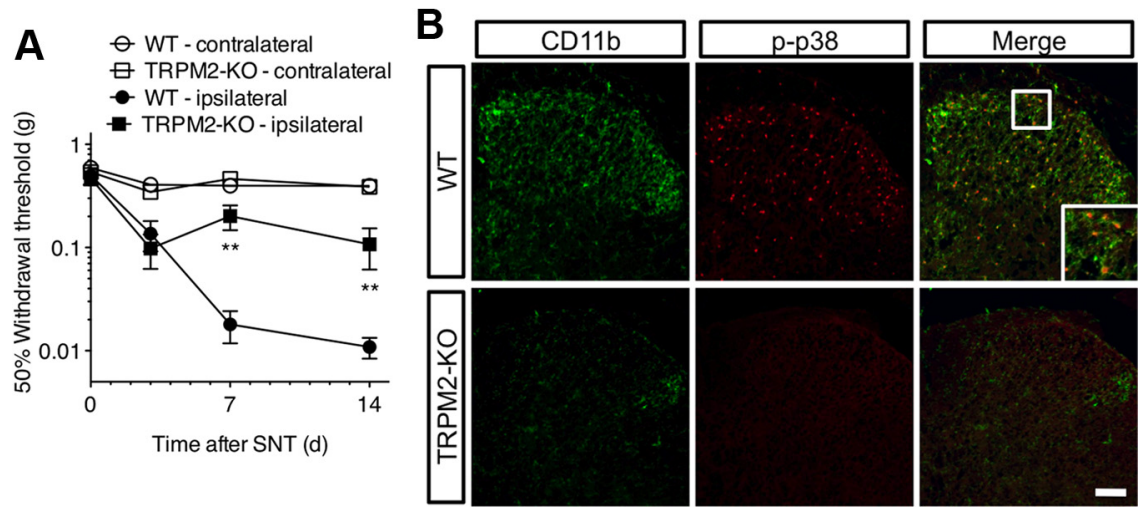

Figure 7. TRPM2 deficiency impaired SNT-induced neuropathic pain and spinal microglial activation. $\boldsymbol{A}$, In the SNT model of neuropathic pain, the $50 \%$ withdrawal threshold to mechanical stimuli in the von Frey filament test was determined in the ipsilateral and contralateral paws of WT and TRPM2-K0 mice $(n=7-8) .{ }^{* *} p<0.01$ between the WT and TRPM2-K0 mice. Data are expressed as means \pm SEM. $\boldsymbol{B}$, Sections of the $L 4$ dorsal spinal cord were double immunofluorescence stained with CD11b (green) and phosphorylated p-38 (p-p38; red) in the ipsilateral spinal dorsal horn of WT and TRPM2-K0 mice 3 d after SNT surgery. Scale bar, $50 \mu \mathrm{m}$. Enlarged images are shown in rectangles.

trophils (Cunha et al., 2005). Therefore, TRPM2 deficiency suppresses CXCL2 production from the resident and recruited macrophages, and thereby reduces neutrophil infiltration to the inflamed sites, although CXCL2 itself does not elicit pain (Rittner et al., 2006). Infiltrated neutrophils play a critical role in the generation of inflammatory pain (Lavich et al., 2006; Cunha et al., 2008). Activated neutrophils aggravate neuronal injury and increase neuronal activity and excitability when cocultured with dissociated DRG cells (Shaw et al., 2008). The blockade of CXCR2, which is the receptor for CXCL1/2 and plays a crucial role in neutrophil infiltration, attenuates in- 

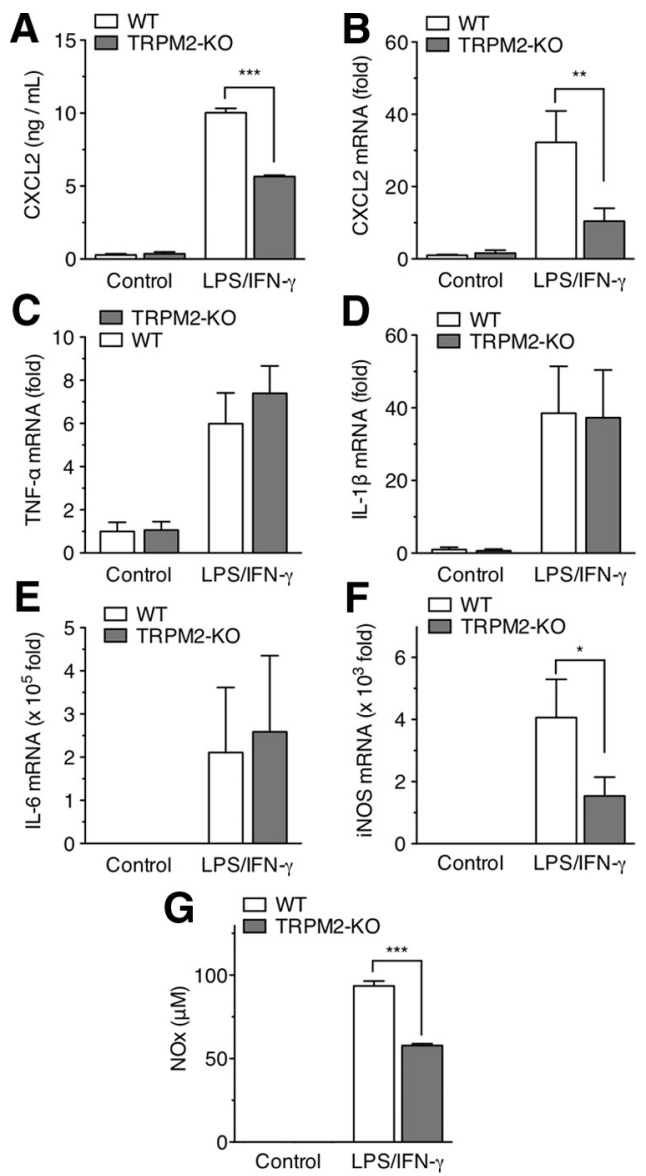

Figure 8. TRPM2 deficiency impairs some LPS/IFN- $\gamma$-induced responses in primary cultured microglia. Cultured microglia derived from WT and TRPM2-KO mice were incubated in the presence or absence of LPS $(100 \mathrm{ng} / \mathrm{ml})$ and IFN- $\gamma(10 \mathrm{ng} / \mathrm{ml})$ for $48 \mathrm{~h}$. $A$, The level of CXCL2 production was measured by ELISA $(n=4-5) \cdot \boldsymbol{B}-\boldsymbol{F}$, The expression levels of CXCL2 $(n=5-6$; $\boldsymbol{B})$, TNF- $\alpha(n=5-6 ; \boldsymbol{C}), \mathrm{IL}-1 \beta(n=5-11 ; \boldsymbol{D}), \mathrm{IL}-6(n=6-7 ; \boldsymbol{E})$, and iNOS $(n=9-11 ; \boldsymbol{F})$ mRNAs were measured by real-time PCR. Each mRNA level was normalized to the $\beta$-actin mRNA level and expressed relative to the control (fold). $G$, The concentration of $N 0$ in the culture supernatants was determined by the Griess reaction $(n=4) .{ }^{*} p<0.05 ;{ }^{* *} p<0.01 ;{ }^{* * *} p<$ 0.001. Data are expressed as mean \pm SEM.

flammatory pain and neutrophil infiltration (Manjavachi et al., 2010). These findings suggest that CXCL2 production from macrophages via TRPM2 activation triggers neutrophil infiltration, which contributes to inflammatory pain. Our findings are consistent with the previous report that the leukocyte rolling inhibitor fucoidin attenuates carrageenan-induced inflammatory pain and neutrophil infiltration without affecting the production of pronociceptive cytokines and chemokines, such as TNF- $\alpha$, IL$1 \beta$, and CXCL1 (Lavich et al., 2006; Cunha et al., 2008). It is conceivable that neutrophils, while not the major source of pronociceptive cytokines and chemokines, are essential for the generation of inflammatory pain. TRPM2 deficiency suppressed CXCL2 production throughout the period of inflammatory and neuropathic pain, while the attenuation of neutrophil infiltration returned to a normal level at $24 \mathrm{~h}$ or later after carrageenan injection or pSNL surgery. These findings raise a possibility that other neutrophil chemotactic factors, such as other CXCL chemokines (CXCL3, CXCL4, CXCL6, and CXCL7, but not CXCL1), leukotriene B4, or complement component C5a (Kobayashi, 2008; Semple et al., 2010), may contribute to the delayed neutrophil infiltration, although the effects of TRPM2 deficiency have not been determined.
TRPM2 deficiency had no effect on the productions of $\mathrm{H}_{2} \mathrm{O}_{2}$, TNF- $\alpha$, and CCL2, which are involved in inflammatory pain (Wang et al., 2004; Scholz and Woolf, 2007; Ren and Dubner, 2010). Some inflammatory cytokines, such as TNF- $\alpha$, and ROS produced from activated macrophages and other immune cells elicit pain directly acting on the primary nociceptive neurons (Schäfers et al. 2003; Andersson et al., 2008; Keeble et al., 2009). However, TRPM2 deficiency had no effect on the TNF- $\alpha$ - and $\mathrm{H}_{2} \mathrm{O}_{2}$-evoked hypersensitivity, suggesting that TRPM2 is not involved in the sensitivity of the primary nociceptive neurons to TNF- $\alpha$ and ROS. Although TNF- $\alpha$ and $\mathrm{H}_{2} \mathrm{O}_{2}$ activate TRPM2 (Hara et al., 2002), exogenous TNF- $\alpha$ - and $\mathrm{H}_{2} \mathrm{O}_{2}$-evoked hypersensitivity is not mediated through TRPM2 in the noninflamed paws, where TRPM2 expression on resident macrophages is low and circulating macrophages are not recruited.

When the axon-myelin-Schwann cell unit in peripheral nerves is disturbed, macrophages and neutrophils are recruited to the injured sites. The recruited macrophages mediate the removal of the cellular debris of degenerating axons and contribute to the peripheral sensitization by producing various pronociceptive mediators (Scholz and Woolf, 2007; Ren and Dubner, 2010). Several lines of evidence suggest critical roles for infiltrated neutrophils in the generation of peripheral sensitization in neuropathic pain (Perkins and Tracey, 2000; Thacker et al., 2007). Our results further support the role of TRPM2 in CXCL2 production and neutrophil infiltration around the injured sciatic nerve, while the contribution of TRPM2 in the peripheral sites may be restricted to the early phase. In contrast, microglial activation in the spinal cord was suppressed throughout the period of neuropathic pain in TRPM2-KO mice. As microglial activation plays a critical role in the induction of neuropathic pain, the prolonged inhibition of spinal microglia by TRPM2 deficiency may largely contribute to the prevention of neuropathic pain. TRPM2 deficiency reduced the CXCL2 and iNOS/NO production in microglia. Peripheral nerve injury-induced neuropathic pain is associated with iNOS induction and NO release from spinal microglia (Kim et al., 2007; Martucci et al., 2008), and a selective iNOS inhibitor attenuates pSNL-induced mechanical allodynia and thermal hyperalgesia (Tanabe et al., 2009). Although the roles of CXCL2 in the spinal cord on neuropathic pain have not been determined, the present data suggest that TRPM2 activation leads to NO and CXCL2 production from microglia, which in turn mediates the generation of central sensitization. However, the suppression of spinal microglial activation may be due to the secondary influence of the decreased peripheral neuroinflammation caused by TRPM2 deficiency.

The present results suggest that the action of TRPM2 on inflammatory processes is facilitated through TRPM2 upregulation. The upregulation of TRPM 2 mRNA in the inflamed and injured sites is caused by both the increased transcription of TRPM2 and the accumulation of circulating macrophages, neutrophils, and other immune cells expressing TRPM2 (Perraud et al., 2001; Sano et al., 2001; Yamamoto et al., 2008; Wehrhahn et al., 2010), although we cannot fully exclude the possibility that the transcripts are increased in other hematopoietic cells or peripheral skin cells. Unlike macrophages and neutrophils, resident microglia expressing TRPM2 are originally abundant in the spinal cord. Peripheral nerve injury leads to activation of resident microglia, which is accompanied by TRPM2 upregulation and increases the population of activated microglia due to proliferation and migration in the spinal cord (Echeverry et al., 2008). Monocytic lineage cells and granulocytes produce abundant ROS, particularly $\mathrm{H}_{2} \mathrm{O}_{2}$, to eliminate invading pathogens. ROS 
are involved critically in the generation of inflammation and play a role in pathological pain (Kim et al., 2004, 2010). Therefore, TRPM2 may be involved in a range of inflammatory and neuropathic pain that arises from $\mathrm{H}_{2} \mathrm{O}_{2}$-mediated inflammation in the peripheral and spinal sites, although TRPM2 is not involved in the $\mathrm{H}_{2} \mathrm{O}_{2}$ production in the inflamed paws. These findings suggest that inflammation-triggered TRPM2 upregulation in peripheral macrophages and spinal microglia exacerbates ROS-mediated inflammation by an autocrine/paracrine pathway through TRPM 2 activation, which contributes to the generation of inflammatory and neuropathic pain.

Recent evidence that TRPM2-KO mice are susceptible to bacterial infection thorough impaired inflammatory responses and uncontrolled bacterial growth further suggests the roles of TRPM2 in immune functions (Knowles et al., 2011). On the other hand, other TRP channels are also involved in the function of macrophages. TRPV2-mediated depolarization triggers actin depolymerization necessary for early phagocytosis, but not LPSinduced TNF- $\alpha$ production in murine macrophages (Link et al., 2010). On the other hand, stimulation of TRPV4 increases $\mathrm{Ca}^{2+}$ influx and the resultant production of superoxide and $\mathrm{NO}$ in alveolar macrophages (Hamanaka et al., 2010). TRPV2-KO mice display normal thermal and mechanical hyperalgesia in peripheral inflammatory and neuropathic pain models (Park et al., 2011), while inflammatory mechanical and hypotonic hyperalgesia is reduced in TRPV4-KO mice (Alessandri-Haber et al., 2006). TRP channels related to the production of proinflammatory mediators from macrophages may contribute to pathological pain. Recent studies demonstrate that macrophages possess other functional channels such as TRPC3 (Tano et al., 2011) and TRPC6 (Finney-Hayward et al., 2010) and store-operated channels (Gao et al., 2010), although their roles in cytokine/chemokine production and pathological pain remain to be elucidated.

In conclusion, the present study revealed the involvement of TRPM2 in pathological pain. TRPM2 expressed in macrophages and microglia aggravates peripheral and spinal pronociceptive inflammatory responses to induce inflammatory and neuropathic pain thorough neuroinflammation-mediated peripheral and central sensitization of the pain-signaling pathway. TRPM2 may be a promising target for the treatment of pathological pain.

\section{References}

Alessandri-Haber N, Dina OA, Joseph EK, Reichling D, Levine JD (2006) A transient receptor potential vanilloid 4-dependent mechanism of hyperalgesia is engaged by concerted action of inflammatory mediators. J Neurosci 26:3864-3874.

Andersson DA, Gentry C, Moss S, Bevan S (2008) Transient receptor potential A1 is a sensory receptor for multiple products of oxidative stress. J Neurosci 28:2485-2494.

Armstrong DA, Major JA, Chudyk A, Hamilton TA (2004) Neutrophil chemoattractant genes KC and MIP-2 are expressed in different cell populations at sites of surgical injury. J Leukoc Bio 75:641-648.

Buelow B, Song Y, Scharenberg AM (2008) The poly(ADP-ribose) polymerase PARP-1 is required for oxidative stress-induced TRPM2 activation in lymphocytes. J Biol Chem 283:24571-24583.

Callahan BL, Gil AS, Levesque A, Mogil JS (2008) Modulation of mechani$\mathrm{cal}$ and thermal nociceptive sensitivity in the laboratory mouse by behavioral state. J Pain 9:174-184.

Chaplan SR, Bach FW, Pogrel JW, Chung JM, Yaksh TL (1994) Quantitative assessment of tactile allodynia in the rat paw. J Neurosci Methods 53:55-63.

Cunha TM, Verri WA Jr, Silva JS, Poole S, Cunha FQ, Ferreira SH (2005) A cascade of cytokines mediates mechanical inflammatory hypernociception in mice. Proc Natl Acad Sci U S A 102:1755-1760.

Cunha TM, Verri WA Jr, Schivo IR, Napimoga MH, Parada CA, Poole S, Teixeira MM, Ferreira SH, Cunha FQ (2008) Crucial role of neutrophils in the development of mechanical inflammatory hypernociception. J Leukoc Biol 83:824-832.

DeLeo JA, Rutkowski MD, Stalder AK, Campbell IL (2000) Transgenic expression of TNF by astrocytes increases mechanical allodynia in a mouse neuropathy model. Neuroreport 11:599-602.

Dixon WJ (1980) Efficient analysis of experimental observations. Annu Rev Pharmacol Toxicol 20:441-462.

Echeverry S, Shi XQ, Zhang J (2008) Characterization of cell proliferation in rat spinal cord following peripheral nerve injury and the relationship with neuropathic pain. Pain 135:37-47.

Finney-Hayward TK, Popa MO, Bahra P, Li S, Poll CT, Gosling M, Nicholson AG, Russell RE, Kon OM, Jarai G, Westwick J, Barnes PJ, Donnelly LE (2010) Expression of transient receptor potential c6 channels in human lung macrophages. Am J Respir Cell Mol Biol 43:296-304.

Gao YD, Hanley PJ, Rinné S, Zuzarte M, Daut J (2010) Calcium-activated $\mathrm{K}^{+}$channel $\left(\mathrm{K}_{\mathrm{Ca}} 3.1\right)$ activity during $\mathrm{Ca}^{2+}$ store depletion and storeoperated $\mathrm{Ca}^{2+}$ entry in human macrophages. Cell Calcium 48:19-27.

Gao YJ, Ji RR (2010) Chemokines, neuronal-glial interactions, and central processing of neuropathic pain. Pharmacol Ther 126:56-68.

Hamanaka K, Jian MY, Townsley MI, King JA, Liedtke W, Weber DS, Eyal FG, Clapp MM, Parker JC (2010) TRPV4 channels augment macrophage activation and ventilator-induced lung injury. Am J Physiol Lung Cell Mol Physiol 299:L353-L362.

Hara Y, Wakamori M, Ishii M, Maeno E, Nishida M, Yoshida T, Yamada H, Shimizu S, Mori E, Kudoh J, Shimizu N, Kurose H, Okada Y, Imoto K, Mori Y (2002) LTRPC2 $\mathrm{Ca}^{2+}$-permeable channel activated by changes in redox status confers susceptibility to cell death. Mol Cell 9:163-173.

Hargreaves K, Dubner R, Brown F, Flores C, Joris J (1988) A new and sensitive method for measuring thermal nociception in cutaneous hyperalgesia. Pain 32:77-88.

Hunskaar S, Hole K (1987) The formalin test in mice: dissociation between inflammatory and non-inflammatory pain. Pain 30:103-114.

Ikeda-Matsuo Y, Ikegaya Y, Matsuki N, Uematsu S, Akira S, Sasaki Y (2005) Microglia-specific expression of microsomal prostaglandin $\mathrm{E}_{2}$ synthase-1 contributes to lipopolysaccharide-induced prostaglandin $\mathrm{E}_{2}$ production. J Neurochem 94:1546-1558.

Kaneko S, Kawakami S, Hara Y, Wakamori M, Itoh E, Minami T, Takada Y, Kume T, Katsuki H, Mori Y, Akaike A (2006) A critical role of TRPM2 in neuronal cell death by hydrogen peroxide. J Pharmacol Sci 101:66-76.

Keeble JE, Bodkin JV, Liang L, Wodarski R, Davies M, Fernandes ES, Coelho Cde F, Russell F, Graepel R, Muscara MN, Malcangio M, Brain SD (2009) Hydrogen peroxide is a novel mediator of inflammatory hyperalgesia, acting via transient receptor potential vanilloid 1-dependent and independent mechanisms. Pain 141:135-142.

Kielian T, Barry B, Hickey WF (2001) CXC chemokine receptor-2 ligands are required for neutrophil-mediated host defense in experimental brain abscesses. J Immunol 166:4634-4643.

Kim D, Kim MA, Cho IH, Kim MS, Lee S, Jo EK, Choi SY, Park K, Kim JS, Akira S, Na HS, Oh SB, Lee SJ (2007) A critical role of toll-like receptor 2 in nerve injury-induced spinal cord glial cell activation and pain hypersensitivity. J Biol Chem 282:14975-14983.

Kim D, You B, Jo EK, Han SK, Simon MI, Lee SJ (2010) NADPH oxidase 2-derived reactive oxygen species in spinal cord microglia contribute to peripheral nerve injury-induced neuropathic pain. Proc Natl Acad Sci U S A 107:14851-14856.

Kim HK, Park SK, Zhou JL, Taglialatela G, Chung K, Coggeshall RE, Chung JM (2004) Reactive oxygen species (ROS) play an important role in a rat model of neuropathic pain. Pain 111:116-124.

Kim SH, Chung JM (1992) An experimental model for peripheral neuropathy produced by segmental spinal nerve ligation in the rat. Pain 50:355-363.

Knowles H, Heizer JW, Li Y, Chapman K, Ogden CA, Andreasen K, Shapland E, Kucera G, Mogan J, Humann J, Lenz LL, Morrison AD, Perraud AL (2011) Transient Receptor Potential Melastatin 2 (TRPM2) ion channel is required for innate immunity against Listeria monocytogenes. Proc Natl Acad Sci U S A 108:11578-11583.

Kobayashi Y (2008) The role of chemokines in neutrophil biology. Front Biosci 13:2400-2407.

Kraft R, Grimm C, Grosse K, Hoffmann A, Sauerbruch S, Kettenmann H, Schultz G, Harteneck C (2004) Hydrogen peroxide and ADP-ribose induce TRPM2-mediated calcium influx and cation currents in microglia. Am J Physiol Cell Physiol 286:C129-C137. 
Lavich TR, Siqueira Rde A, Farias-Filho FA, Cordeiro RS, Rodrigues e Silva PM, Martins MA (2006) Neutrophil infiltration is implicated in the sustained thermal hyperalgesic response evoked by allergen provocation in actively sensitized rats. Pain 125:180-187.

Link TM, Park U, Vonakis BM, Raben DM, Soloski MJ, Caterina MJ (2010) TRPV2 has a pivotal role in macrophage particle binding and phagocytosis. Nat Immunol 11:232-239.

Malmberg AB, Basbaum AI (1998) Partial sciatic nerve injury in the mouse as a model of neuropathic pain: behavioral and neuroanatomical correlates. Pain 76:215-222.

Manjavachi MN, Quintão NL, Campos MM, Deschamps IK, Yunes RA, Nunes RJ, Leal PC, Calixto JB (2010) The effects of the selective and non-peptide CXCR2 receptor antagonist SB225002 on acute and longlasting models of nociception in mice. Eur J Pain 14:23-31.

Martucci C, Trovato AE, Costa B, Borsani E, Franchi S, Magnaghi V, Panerai AE, Rodella LF, Valsecchi AE, Sacerdote P, Colleoni M (2008) The purinergic antagonist PPADS reduces pain related behaviours and interleukin-1 $\beta$, interleukin-6, iNOS and nNOS overproduction in central and peripheral nervous system after peripheral neuropathy in mice. Pain 137:81-95.

McNamara CR, Mandel-Brehm J, Bautista DM, Siemens J, Deranian KL, Zhao M, Hayward NJ, Chong JA, Julius D, Moran MM, Fanger CM (2007) TRPAl mediates formalin-induced pain. Proc Natl Acad Sci U S A 104:13525-13530.

Nagamine K, Kudoh J, Minoshima S, Kawasaki K, Asakawa S, Ito F, Shimizu N (1998) Molecular cloning of a novel putative $\mathrm{Ca}^{2+}$ channel protein (TRPC7) highly expressed in brain. Genomics 54:124-131.

Nazıroğlu M, Özgül C, Çelik Ö, Çĭg B, Sözbir E (2011) Aminoethoxydiphenyl borate and flufenamic acid inhibit $\mathrm{Ca}^{2+}$ influx through TRPM2 channels in rat dorsal root ganglion neurons activated by ADP-ribose and rotenone. J Membr Biol 241:69-75.

Ohana L, Newell EW, Stanley EF, Schlichter LC (2009) The $\mathrm{Ca}^{2+}$ releaseactivated $\mathrm{Ca}^{2+}$ current $\left(\mathrm{I}_{\mathrm{CRAC}}\right)$ mediates store-operated $\mathrm{Ca}^{2+}$ entry in rat microglia. Channels 3:129-139.

Park U, Vastani N, Guan Y, Raja SN, Koltzenburg M, Caterina MJ (2011) TRP vanilloid 2 knock-out mice are susceptible to perinatal lethality but display normal thermal and mechanical nociception. J Neurosci 31:11425-11436.

Perkins NM, Tracey DJ (2000) Hyperalgesia due to nerve injury: role of neutrophils. Neuroscience 101:745-757.

Perraud AL, Fleig A, Dunn CA, Bagley LA, Launay P, Schmitz C, Stokes AJ, Zhu Q, Bessman MJ, Penner R, Kinet JP, Scharenberg AM (2001) ADPribose gating of the calcium-permeable LTRPC2 channel revealed by Nudix motif homology. Nature 411:595-599.

Ren K, Dubner R (2010) Interactions between the immune and nervous systems in pain. Nat Med 16:1267-1276.

Rittner HL, Brack A, Machelska H, Mousa SA, Bauer M, Schäfer M, Stein C (2001) Opioid peptide-expressing leukocytes: identification, recruitment, and simultaneously increasing inhibition of inflammatory pain. Anesthesiology 95:500-508.

Rittner HL, Mousa SA, Labuz D, Beschmann K, Schäfer M, Stein C, Brack A
(2006) Selective local PMN recruitment by CXCL1 or CXCL2/3 injection does not cause inflammatory pain. J Leukoc Biol 79:1022-1032.

Sano Y, Inamura K, Miyake A, Mochizuki S, Yokoi H, Matsushime H, Furuichi $\mathrm{K}$ (2001) Immunocyte $\mathrm{Ca}^{2+}$ influx system mediated by LTRPC2. Science 293:1327-1330.

Schäfers M, Lee DH, Brors D, Yaksh TL, Sorkin LS (2003) Increased sensitivity of injured and adjacent uninjured rat primary sensory neurons to exogenous tumor necrosis factor-alpha after spinal nerve ligation. J Neurosci 23:3028-3038.

Scholz J, Woolf CJ (2007) The neuropathic pain triad: neurons, immune cells and glia. Nat Neurosci 10:1361-1368.

Seltzer Z, Dubner R, Shir Y (1990) A novel behavioral model of neuropathic pain disorders produced in rats by partial sciatic nerve injury. Pain 43:205-218.

Semple BD, Kossmann T, Morganti-Kossmann MC (2010) Role of chemokines in CNS health and pathology: a focus on the CCL2/CCR2 and CXCL8/CXCR2 networks. J Cereb Blood Flow Metab 30:459-473.

Shaw SK, Owolabi SA, Bagley J, Morin N, Cheng E, LeBlanc BW, Kim M, Harty P, Waxman SG, Saab CY (2008) Activated polymorphonuclear cells promote injury and excitability of dorsal root ganglia neurons. Exp Neurol 210:286-294.

Tanabe M, Nagatani Y, Saitoh K, Takasu K, Ono H (2009) Pharmacological assessments of nitric oxide synthase isoforms and downstream diversity of NO signaling in the maintenance of thermal and mechanical hypersensitivity after peripheral nerve injury in mice. Neuropharmacology $56: 702-708$

Tano JY, Smedlund K, Lee R, Abramowitz J, Birnbaumer L, Vazquez G (2011) Impairment of survival signaling and efferocytosis in TRPC3deficient macrophages. Biochem Biophys Res Commun 410:643-647.

Tekamp-Olson P, Gallegos C, Bauer D, McClain J, Sherry B, Fabre M, van Deventer S, Cerami A (1990) Cloning and characterization of cDNAs for murine macrophage inflammatory protein 2 and its human homologues. J Exp Med 172:911-919.

Thacker MA, Clark AK, Marchand F, McMahon SB (2007) Pathophysiology of peripheral neuropathic pain: immune cells and molecules. Anesth Analg 105:838-847.

Togashi K, Hara Y, Tominaga T, Higashi T, Konishi Y, Mori Y, Tominaga M (2006) TRPM2 activation by cyclic ADP-ribose at body temperature is involved in insulin secretion. EMBO J 25:1804-1815.

Wang ZQ, Porreca F, Cuzzocrea S, Galen K, Lightfoot R, Masini E, Muscoli C, Mollace V, Ndengele M, Ischiropoulos H, Salvemini D (2004) A newly identified role for superoxide in inflammatory pain. J Pharmacol Exp Ther 309:869-878.

Wehrhahn J, Kraft R, Harteneck C, Hauschildt S (2010) Transient receptor potential melastatin 2 is required for lipopolysaccharide-induced cytokine production in human monocytes. J Immunol 184:2386-2393.

Yamamoto S, Shimizu S, Kiyonaka S, Takahashi N, Wajima T, Hara Y, Negoro T, Hiroi T, Kiuchi Y, Okada T, Kaneko S, Lange I, Fleig A, Penner R, Nishi M, Takeshima H, Mori Y (2008) TRPM2-mediated $\mathrm{Ca}^{2+}$ influx induces chemokine production in monocytes that aggravates inflammatory neutrophil infiltration. Nat Med 14:738-747. 